\title{
Performance Evaluation and Process Optimization of Potato Drying using Hot Air Oven
}

\author{
Shahzad Faisal ${ }^{1 *}$, Ruhi Tabassum ${ }^{2}$ and Vishal Kumar ${ }^{3}$ \\ ${ }^{1}$ Assistant professor, Division of Agricultural Engineering, SKUAST-K, Srinagar, India \\ ${ }^{2} E x$. B. Tech students of Agricultural Engineering at SKUAST-K, Srinagar, India \\ ${ }^{3}$ Assistant professor, College of Agricultural Engineering, RAU, Pusa, India
}

\begin{abstract}
The effect of various process parameters on drying behavior of Potato (Solanum tuberosum) was studied, and the optimization of process parameters based on quality was investigated. Experiments were conducted to characterize the drying behavior of Potato cubes at various temperatures, potato cube sizes and blanching chemical treatments. The various drying models were evaluated for their suitability and Midilli's model was found to be best describing the drying characteristics of Potato cubes. A full second order model was developed for all the response variables, viz. Rehydration ratio, shrinkage percentage and mean sensory scores of overall acceptability and found to be significant at $1 \%$ level of significance. The effect of process variables was investigated at individual, linear, interactive and quadratic levels for each response. The data was optimized by 'Design Expert 7.0' for all the responses. Compromise optimum level of process variables for the responses were $80^{\circ} \mathrm{C}(1), 1 \mathrm{~cm}$ cube size $(-0.87)$ \& KMS (0). The corresponding values of the responses were $4.584,24.979 \& 5.000$ respectively.
\end{abstract}

Keywords: Potato cubes; Rehydration ratio; Shrinkage Percentage; Overall Acceptability; Optimization

\section{Introduction}

Potato (Solanum tuberosum L.) is one of the unique and most potential crops having high productivity, supplementing major food requirement in the world. It is rich in carbohydrates, proteins, phosphorus, calcium, vitamin $\mathrm{C}, \beta$-carotene and has high protein calorie ratio. Amongst the world's important food crops, Potato is the fourth important food crop after wheat, rice and maize because of its' great yield potential and high nutritive value. The ratio of protein to carbohydrate is higher in potato than in many cereals and other tuber crops [1]. It constitutes nearly half of the world's annual output of all root and tuber crops and has always remained in the top ten since last twenty years. India ranks fourth in area with 14 lakh hectares and the third largest country in the world in production of potato after China and Russian federation with a production of 294.94 million tonnes and productivity of 17.86 tonnes per hectare.

Potato drying was undertaken because it is a popular daily product and despite the availability of indigenous raw potatoes for snack production, Jammu and Kashmir imports products worth Rupees 1000 million every year. The valley region produces more than 20,000 tons of potatoes annually and is readily available throughout the year at a cheap price. The major commercial variety grown in Kashmir is "Kufri Jyoti" which is very suitable for instant flakes and chips. So there is a huge scope for the processing industries of potatoes in Kashmir.

Drying is the process of removal of water or any other solvent by evaporation from a solid, semi-solid or liquid material [2]. It is a thermo-physical and physico-chemical process whose dynamic principles are governed by heat and mass transfer laws, both inside and outside the products. In the most common cases, a gas stream, like air stream, applies the heat by convection and carries away the vapor as humidity. Now as the heat is conducted through the food, the temperature within the food rises; being a simultaneous heat and mass transfer phenomenon it increases the water vapor pressure of the moisture present within the food matrix. The medium used for drying the food i.e. hot air in convective drying has a low value of water vapor pressure at high temperature; which creates a vapor pressure gradient between the moisture present in the food and the moisture in air and this gradient is responsible for the moisture migration or the mass transfer phenomenon.

Drying is generally carried out for two main reasons, one to reduce the water activity which eventually increase the shelf life of food and second to reduce the weight and bulk of food for cheaper transport and storage. Drying methods can be broadly classified into solar drying and mechanical drying. Although it's difficult to classify all the possible drying methods, some of the basic and commonly used methods are: convective drying, contact drying, cabinet drying, fluidized bed drying, pneumatic drying, osmotic drying, freeze drying, radiation drying, super-heated steam drying etc.

Potato being a high moisture food is rich in enzyme namely peroxidases and cannot be sun-dried, as the traditional sun drying is a slow process and makes such food materials susceptible to fungal growth. It may also result in the loss of product quality from color degradation, microbial growth and poor rehydration etc. Thus the drying process must be undertaken in a closed dryer. Being the better method for drying the high moisture foods, use of hot air oven for drying of potato cubes was analyzed. The main part of the present study was to use the hot air oven as a cabinet dryer for drying the potato cubes and evaluating its performance for quality dried product. A hot air oven fitted with fan for circulation of air within the cabinet of oven is similar to that of a Hot Air Cabinet Dryer. Keeping this point in view the experimental set up was chosen for the study.

*Corresponding author: Shahzad Faisal, Assistant professor, Division of Agricultural Engineering, SKUAST-K, Srinagar, India, Tel: 0091-9697937920; E-mail: sfaisal@skuastkashmir.ac.in

Received July 23, 2013; Accepted September 27, 2013; Published October 08 2013

Citation: Faisal S, Tabassum R, Kumar V (2013) Performance Evaluation and Process Optimization of Potato Drying using Hot Air Oven. J Food Process Technol 4: 273. doi:10.4172/2157-7110.1000273

Copyright: ( 2013 Faisal S, et al. This is an open-access article distributed unde the terms of the Creative Commons Attribution License, which permits unrestricted use, distribution, and reproduction in any medium, provided the original author and source are credited. 


\section{Materials and Methods}

The drying performance of a hot air oven was evaluated for potato cubes of different sizes, at different temperatures and different pretreatments. The quality parameters viz. rehydration ratio, percentage shrinkage and over all acceptability of dried product were evaluated and optimized. Details of the material, methodology and the experimental design are as below:

\section{Preliminary experiments}

In order to determine the levels of variables as well as to assess the feasibility of the study, various preliminary experiments were carried out in the processing laboratory of division of Agriculture Engineering as follows:

In the very first phase of preliminary experiments the oven was tested at experimental temperatures viz. 60,70 and $80^{\circ} \mathrm{C}$ and the time taken by the oven to attain the set temperature was noted. It was found for all the experimental temperatures that oven is taking approximately one hour to equilibrate with the required temperature. The oven attained the set temperature with a deviation of $\pm 1^{\circ} \mathrm{C}$. The central tray was found to be satisfactory for the drying purpose as there was almost uniform air flow pattern measured through anemometer. After selection of tray, temperature distribution over the surface was determined by placing digital temperature meters at the perimeter and center of the tray. The result of which shows that there is only variation of $\pm 0.5^{\circ} \mathrm{C}$. The quantity of chemicals to be used for blanching was calculated by using the concentration of chemicals as per the reviews on the effect of pretreatments on potato cubes [3]. Blanching experiments were conducted in which solid to syrup ratio was kept at 1:3 and dipping time was 5 minutes as suggested by several research workers [4].

\section{Experimental design}

The variables of the study were: drying air temperature, potato cube size and the different blanching chemicals. The ranges of the variables under study were selected on the basis of earlier research work, and the constraints related with the hot air drying of potato. The three levels of each variable were taken and reported in Table 1 . A $3 \times 3$ full factorial design was used to decide the combination of independent variable levels in each experiment. The plan consists of 27 experiments, and the total number of experiments was divided into three groups based on the cube sizes.

\section{Determination of moisture content}

Moisture content of potato cubes was determined initially using infra- red moisture meter, manufactured by Tashabah India Co. Infrared moisture meter used was a semi-automatic moisture meter, which gave moisture content value directly on wet basis. In experiments, weight loss of samples was measured using digital balance having $5 \mathrm{~kg}$ capacity with a least count of $0.1 \mathrm{~g}$. Weight differential was converted into corresponding moisture loss for calculating moisture content value at each interval of drying time.

\section{Equilibrium moisture content}

The equilibrium moisture content was found by trial and error method. The equilibrium moisture content was tried at 1 and $2 \%$ less than the final moisture content sustained during the experiments. The drying models were linearized and regression analysis carried out, on the basis of linear regression it was found that $1 \%$ less value gave the best result, which confirm the findings of Burande [5], Pandey [6] and Goyal [7].

\begin{tabular}{|c|c|c|}
\hline Temperature & Size of potato cubes & Chemicals for blanching \\
\hline \multirow{9}{*}{$60^{\circ} \mathrm{C}$} & \multirow{3}{*}{$1 \mathrm{~cm}^{3}$} & $\mathrm{NaCl}$ \\
\hline & & KMS \\
\hline & & $\mathrm{Na}_{2} \mathrm{~S}_{2} \mathrm{O}_{5}$ \\
\hline & \multirow{3}{*}{$1.5 \mathrm{~cm}^{3}$} & $\mathrm{NaCl}$ \\
\hline & & KMS \\
\hline & & $\mathrm{Na}_{2} \mathrm{~S}_{2} \mathrm{O}_{5}$ \\
\hline & \multirow{3}{*}{$2 \mathrm{~cm}^{3}$} & $\mathrm{NaCl}$ \\
\hline & & KMS \\
\hline & & $\mathrm{Na}_{2} \mathrm{~S}_{2} \mathrm{O}_{5}$ \\
\hline \multirow{9}{*}{$70^{\circ} \mathrm{C}$} & \multirow{3}{*}{$1 \mathrm{~cm}^{3}$} & $\mathrm{NaCl}$ \\
\hline & & KMS \\
\hline & & $\mathrm{Na}_{2} \mathrm{~S}_{2} \mathrm{O}_{5}$ \\
\hline & \multirow{3}{*}{$1.5 \mathrm{~cm}^{3}$} & $\mathrm{NaCl}$ \\
\hline & & KMS \\
\hline & & $\mathrm{Na}_{2} \mathrm{~S}_{2} \mathrm{O}_{5}$ \\
\hline & \multirow{3}{*}{$2 \mathrm{~cm}^{3}$} & $\mathrm{NaCl}$ \\
\hline & & KMS \\
\hline & & $\mathrm{Na}_{2} \mathrm{~S}_{2} \mathrm{O}_{5}$ \\
\hline \multirow{9}{*}{$80^{\circ} \mathrm{C}$} & \multirow{3}{*}{$1 \mathrm{~cm}^{3}$} & $\mathrm{NaCl}$ \\
\hline & & KMS \\
\hline & & $\mathrm{Na}_{2} \mathrm{~S}_{2} \mathrm{O}_{5}$ \\
\hline & \multirow{3}{*}{$1.5 \mathrm{~cm}^{3}$} & $\mathrm{NaCl}$ \\
\hline & & KMS \\
\hline & & $\mathrm{Na}_{2} \mathrm{~S}_{2} \mathrm{O}_{5}$ \\
\hline & \multirow{3}{*}{$2 \mathrm{~cm}^{3}$} & $\mathrm{NaCl}$ \\
\hline & & KMS \\
\hline & & $\mathrm{Na}_{2} \mathrm{~S}_{2} \mathrm{O}_{5}$ \\
\hline
\end{tabular}

Note: $\mathrm{K}_{2} \mathrm{~S}_{2} \mathrm{O}_{5}$ or $\mathrm{KMS}$ : Potassium Meta Bisulphite, $\mathrm{NaCl}$ : Sodium Chloride $\mathrm{Na}_{2} \mathrm{~S}_{2} \mathrm{O}_{5}$ : Sodium Meta Bisulphite

Table 1: Variables of the study.

\section{Drying models}

Since the moisture ratio curve can better explain the drying behavior than that of moisture content curve, as the initial was one in each of the experiment. These moisture ratio values were used to predict the drying model for the samples of potato. The following models were tried to describe the drying characteristics of Potato cubes [8].

$$
\begin{array}{lc}
\text { MR }=a+b \ln (t) & \text { Logarithmic model } \\
\text { MR }=e^{-k t^{n}} & \text { Page's model } \\
\text { MR }=A t^{b} & \text { Power law model } \\
\text { MR }=a e^{-k t}+(1-a) e^{-k a t} & \text { Two term exponential model } \\
\text { MR }=\mathrm{ae}^{-\mathrm{kt}^{n}+b t} & \text { Midilli model }
\end{array}
$$

These models were fitted in the experimental data using nonlinear regression technique. The comparison of the applicability of all five models was done on the basis of standard error of estimation (SEE) and coefficient of determination $\left(\mathrm{R}^{2}\right)$.

\section{Quality parameters}

The quality evaluation of the dried product was carried out on the basis of response variables viz. Rehydration Ratio, Shrinkage Percentage and the Overall Acceptability.

\section{Rehydration ratio}

Ranganna [9] reported that for rehydration of fruits and vegetables any general timing cannot be specified due to variations in the chemical composition and processing techniques for the commodities. 
Rehydration time was therefore standardized through trial runs for the dehydrated potato cubes to be produced during the study.

For the Rehydration test, 20 min. was found to be optimum time as there was no significant weight gain after $20 \mathrm{~min}$. A sample of $2 \mathrm{~g}$ was dipped in $100 \mathrm{ml}$ of boiling water $\left(98^{\circ} \mathrm{C}\right)$ for $20 \mathrm{~min}$. and then allowed to cool to the room temperature and the final weight of the cooled samples was noted.

\section{Shrinkage percentage}

The shrinkage percentage is a drying quality assessing parameter and it must be least for better drying as it directly affects the rehydration quality of the dried product. The shrinkage percentage was calculated after determining the size of the potato cubes before and after drying using an electronic vernier caliper. Shrinkage Percentage was calculated using the below given equation:

\section{Over all acceptability}

Over all acceptability was calculated with the help of a test panel consisting of ten panelist of different age groups and having different eating habits. The Over All acceptability evaluation was carried out on the basis of a 5 point scale Indian standard (IS: 6273, 1971). The score sheets were provided with the product and panelists were requested to mark the product according to their liking. Then the average scores of the panelists were computed for different characters.

\section{Optimization}

The optimization of parameters for different response was carried out by using digital computer. Using the different response-data measurements for all the experimental runs, the response matrix and design matrix was prepared. A multiple linear regression was carried out in Minitab 13 to obtain the coefficients of full second order model along with the detailed statistics. Design Expert 7.0 software was also used to carry out the optimization of linear as well as compromised optimum values for the response variables.

\section{Results and Discussion}

Experiments were conducted to characterize the effect of pretreatments on drying behaviour of $1.0,1.5$ and $2.0 \mathrm{~cm}$ potato cubes and optimization of parameters for quality dried product obtained through a hot air drier. The Midilli Equation was found to be best suitable for discussing the drying behaviour of potato cubes of different Sizes. The data obtained for different pretreatments and drying temperature was optimized on the basis of response variables viz. Rehydration ratio, Percentage shrinkage and mean sensory score of overall acceptability.

\section{Drying characteristics}

After pretreatments, the samples were dried up to the safe level of moisture content, which is around 5-6 \% on dry weight basis for high moisture foods, reported by different researchers. The moisture content, moisture ratio and drying rate at 30 minutes time interval were calculated and used for studying the drying behavior.

It was seen that for the drying at different temperatures the moisture loss increased with the increase in temperature. And for the cubes of same size and treated with the same chemical, it was observed that the final moisture content obtained was least at $80^{\circ} \mathrm{C}$ as shown in Figures 1-3. For cubes of different sizes and at different drying times the type of the chemical used for blanching affected the rate of moisture loss and the rate being maximum for $\mathrm{NaCl}$ and minimum for $\mathrm{NaMS}$.

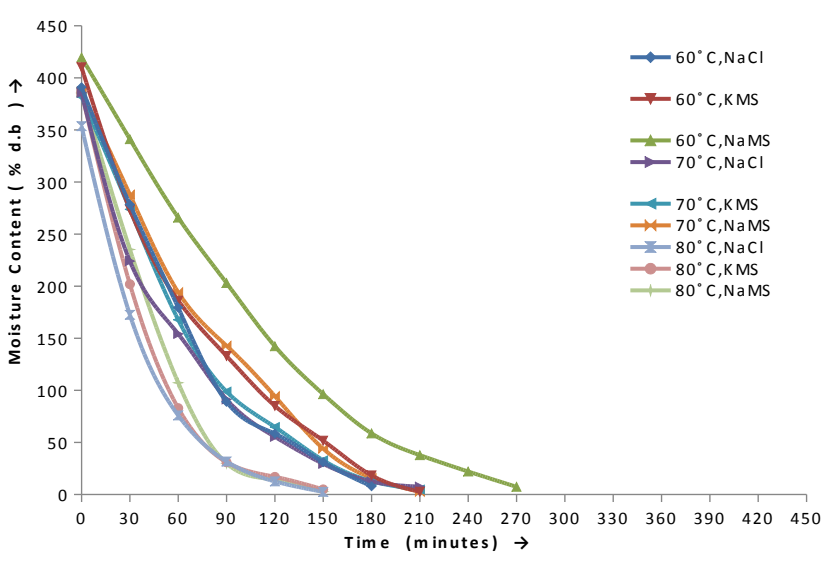

Figure 1: Effect of various Temperatures and Chemical treatments on Moisture content of Potato cubes of $1 \mathrm{~cm}$ size.

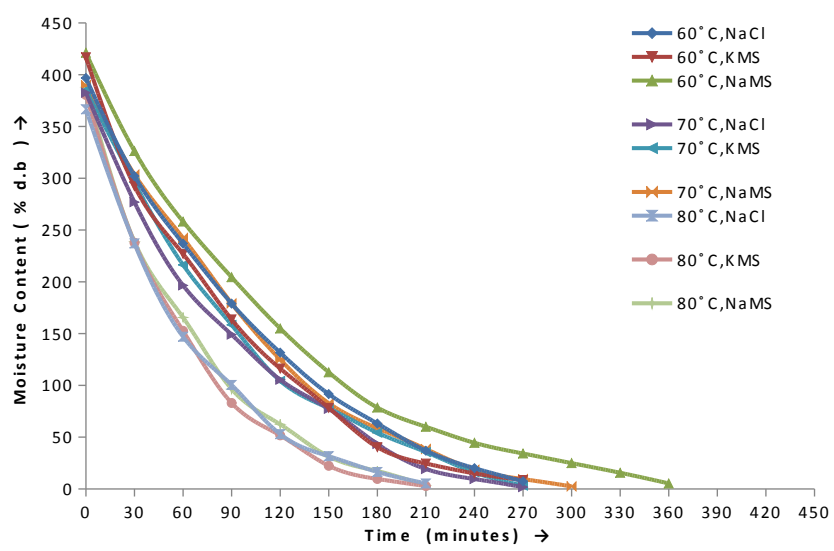

Figure 2: Effect of various Temperatures and Chemical treatments on Moisture content of Potato cubes of $1.5 \mathrm{~cm}$ size.

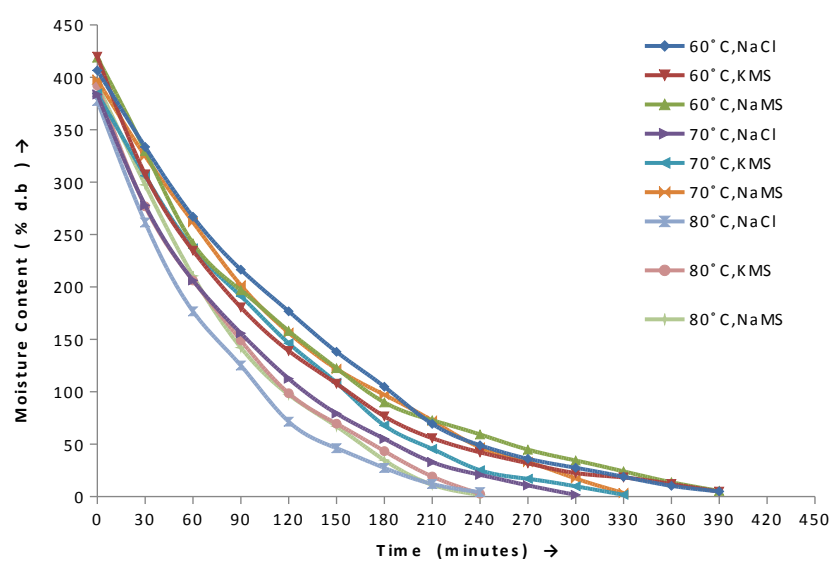

Figure 3: Effect of various Temperatures and Chemical treatments on Moisture content of Potato cubes of $2 \mathrm{~cm}$ size.

The moisture ratio value at zero time of drying was one and on successive drying, it decreased non-linearly. So these curves better describe the effect of variables on drying as compared to moisture content curves, as the initial moisture contents vary for different 
experiments while as the initial moisture ratio was same for all experiments.

The drying rate curves for the experiments shows that for similar drying conditions large sized samples require much more drying time as compared to small sized cubes owing to longer distance for the moisture to travel through the large sized potato cubes.

\section{Calculation of best fit model to characterize the drying behavior of potato cubes}

Drying models were fitted to the experimental data in their non-linearized forms using non-linear regression technique. The comparison of the applicability of all the five models was done on the basis of standard error of estimation (SEE) and coefficient of determination $\left(\mathrm{R}^{2}\right)$. The model constant along with detailed statistical analysis including coefficient of determination and standard error of estimation were calculated for three sizes. Average of $\mathrm{R}^{2}$ and SEE for different sizes and the models are given in Table 2.

Table 2 indicates that the standard error for estimation was the least in Midilli's model as compared to other models for all conditions of experiments, as well as the coefficient of determination was highest in Midilli's model as compared to all other models. Thus on the basis of $\mathrm{R}^{2}$ and SEE, the Midilli's model is found to be more satisfactory than the other models for experimental data.

\section{Effect of drying on rehydration ratio}

The maximum and minimum rehydration ratios were affected by all the three parameters, not by an individual parameter. The larger value of rehydration ratio is the desirable characteristic of the dried samples and it was found to be maximum for a combination of $1 \mathrm{~cm}$ potato cube size, $\mathrm{NaCl}$ as the blanching chemical and at $80^{\circ} \mathrm{C}$ drying temperature.

ANOVA of the regression of second order model for the rehydration ratio are given in Table 3.

The experimental data of the rehydration ratio was fitted in the second order model and the regression coefficient and probability of factors influencing the response at linear, quadratic and interactive levels are reported in Table 4 . The predicted values of rehydration ratio are computed by the model for all the experimental conditions to assess the difference between observed and predicted values as reported in Table 5 .

The coefficient with P-value less than $1 \%$ and 5\%, affect the response at the respective level of significance. The coefficient with P-value more than $10 \%$ was considered as insignificant. The sign and magnitude of the coefficients indicate the effect of variable on the response. Negative sign of the coefficient indicates a decrease in the response when the level of that variable is increased while positive sign indicates increase in the response with increase in the level of the variable.

The effect of drying air temperature, cube size and chemical treatment was significant at $\mathrm{P}<0.01$. In quadratic terms, drying air temperature was significantly effective at $\mathrm{P}<0.1$, while the sample size was significantly effective at $\mathrm{P}<0.01$ and the quadratic terms of the effect of chemical treatment was not significant on the rehydration value. The interaction of drying air temperature, and cube size was significant at $\mathrm{P}<0.1$ and the interaction of the other combinations was insignificant on the rehydration ratio.

The combined effect of parameters at linear, square and interactive levels on rehydration ratio is reported in Table 6. For individual terms, the combined effect of all three variables is significant at $\mathrm{F}<0.01$. For the linear terms, the combined effect of temperature, cube size and the blanching chemical are all significant at $\mathrm{F}<0.01$. In quadratic terms also all the three variables are significant at $\mathrm{F}<0.01$. The interactive terms were not showing any significant combined effect for all the combinations of the variables.

\section{Optimization of rehydration ratio}

The results of optimization are shown in Table 7. The optimum values of rehydration ratio was found to be 4.84 at the temperature of

\begin{tabular}{|c|c|c|c|c|c|}
\hline Statistical parameters & Pages Model & Logarithmic Model & Midilli Model & Power Law Model & Two-Term Exponential Model \\
\hline$R^{2}$ & 99.70 & 98.78 & 99.88037 & 90.1663 \\
\hline SEE & 0.018348 & 0.027627 & 0.014298 & 0.083034 \\
\hline
\end{tabular}

Table 2: Average value of coefficient of determination and standard error of estimation of moisture ratio models for various cube sizes.

\begin{tabular}{|c|c|c|c|c|}
\hline Source & DF & SS & MS & P \\
\hline Regression & 9 & 15.5486 & 1.7276 & 276.86 \\
\hline Residual Error & 17 & 0.1061 & 0.0062 & \\
\hline Total & 26 & 15.6547 & \\
\hline
\end{tabular}

Table 3: ANOVA of full second order model for Rehydration ratio.

\begin{tabular}{|c|c|c|}
\hline Predictor & Coefficient & P \\
\hline Constant & 3.60566 & 0.000 \\
\hline$X_{1}$ & 0.32167 & 0.000 \\
\hline$X_{2}$ & -0.8572 & 0.000 \\
\hline$X_{3}$ & -0.126112 & 0.000 \\
\hline$X_{1}^{2}$ & 0.05500 & 0.106 \\
\hline$X_{2}^{2}$ & -0.13833 & 0.000 \\
\hline$X_{3}^{2}$ & 0.04833 & 0.152 \\
\hline$X_{1} X_{2}$ & 0.065 \\
\hline$X_{1} X_{3}$ & 0.04500 & \\
\hline$X_{2} X_{3}$ & -0.01167 & \\
\hline
\end{tabular}

Table 4: Regression coefficient of full second order model for rehydration ratio for different samples. 
Citation: Faisal S, Tabassum R, Kumar V (2013) Performance Evaluation and Process Optimization of Potato Drying using Hot Air Oven. J Food Process Technol 4: 273. doi:10.4172/2157-7110.1000273

Page 5 of 9

\begin{tabular}{|c|c|c|c|c|c|}
\hline \multirow{2}{*}{ Expt. No. } & \multirow{2}{*}{$X_{1}$} & \multirow{2}{*}{$x_{2}$} & \multirow{2}{*}{$x_{3}$} & \multicolumn{2}{|c|}{$\mathbf{R R}$} \\
\hline & & & & Obs. & Pred. \\
\hline 1 & -1 & -1 & -1 & 4.2 & 4.265 \\
\hline 2 & -1 & -1 & 0 & 4.1 & 4.103 \\
\hline 3 & -1 & -1 & 1 & 4.03 & 4.038 \\
\hline 4 & -1 & 0 & -1 & 3.6 & 3.502 \\
\hline 5 & -1 & 0 & 0 & 3.3 & 3.339 \\
\hline 6 & -1 & 0 & 1 & 3.23 & 3.273 \\
\hline 7 & -1 & 1 & -1 & 2.45 & 2.462 \\
\hline 8 & -1 & 1 & 0 & 2.34 & 2.298 \\
\hline 9 & -1 & 1 & 1 & 2.26 & 2.232 \\
\hline 10 & 0 & -1 & -1 & 4.49 & 4.498 \\
\hline 11 & 0 & -1 & 0 & 4.32 & 4.325 \\
\hline 12 & 0 & -1 & 1 & 4.28 & 4.248 \\
\hline 13 & 0 & 0 & -1 & 3.88 & 3.780 \\
\hline 14 & 0 & 0 & 0 & 3.67 & 3.606 \\
\hline 15 & 0 & 0 & 1 & 3.59 & 3.528 \\
\hline 16 & 0 & 1 & -1 & 2.66 & 2.785 \\
\hline 17 & 0 & 1 & 0 & 2.53 & 2.610 \\
\hline 18 & 0 & 1 & 1 & 2.49 & 2.532 \\
\hline 19 & 1 & -1 & -1 & 4.89 & 4.841 \\
\hline 20 & 1 & -1 & 0 & 4.65 & 4.656 \\
\hline 21 & 1 & -1 & 1 & 4.58 & 4.568 \\
\hline 22 & 1 & 0 & -1 & 4.03 & 4.168 \\
\hline 23 & 1 & 0 & 0 & 3.96 & 3.982 \\
\hline 24 & 1 & 0 & 1 & 3.81 & 3.893 \\
\hline 25 & 1 & 1 & -1 & 3.32 & 3.219 \\
\hline 26 & 1 & 1 & 0 & 3.08 & 3.032 \\
\hline 27 & 1 & 1 & 1 & 2.98 & 2.942 \\
\hline
\end{tabular}

Table 5: Effect of drying on rehydration ratio.

\begin{tabular}{|c|c|c|c|c|}
\hline \multicolumn{2}{|c|}{ SOURCE } & Degrees of Freedom & SS & MSS \\
\hline & $\mathrm{X}_{1}$ & 4 & 1.9065 & 0.476625 \\
\cline { 2 - 5 } & $\mathrm{X}_{2}$ & 4 & 13.366 & 3.3415 \\
\cline { 2 - 5 } Individual & $\mathrm{X}_{3}$ & 4 & 0.3019 & .07547 \\
\hline Linear & $\mathrm{X}_{1}, \mathrm{X}_{2}, \mathrm{X}_{3}$ & 3 & 15.3756 & 5.1252 \\
\hline Quadratic & $\left(\mathrm{X}_{1}\right)^{2},\left(\mathrm{X}_{2}\right)^{2},\left(\mathrm{X}_{3}\right)^{2}$ & 3 & 0.147 & 0.049 \\
\hline Interactive & $\left(\mathrm{X}_{1} \mathrm{X}_{2}\right),\left(\mathrm{X}_{2} \mathrm{X}_{3}\right),\left(\mathrm{X}_{1} \mathrm{X}_{3}\right)$ & 3 & 0.0259 & 0.000863 \\
\hline
\end{tabular}

$\mathrm{F}_{(4,17,0.01)}=4.67, \mathrm{~F}_{(4,17,0.05)}=2.97, \mathrm{~F}_{(3,17,0.01)}=5.19, \mathrm{~F}_{(3,17,0.05)}=3.20$

Significant at: ${ }^{* *} \mathrm{~F}<0.01{ }^{*} \mathrm{~F}<0.05$

Table 6: ANOVA for total effect of individual parameter, linear, interactive and square terms on Rehydration ratio for different samples.

\begin{tabular}{|c|c|c|c|c|c|}
\hline Temperature & \multicolumn{2}{|l|}{ Size } & Chemicals & Rehydration Ratio & Desirability \% \\
\hline $1.00\left(80^{\circ} \mathrm{C}\right)$ & $-1.00(1 \mathrm{~cm})$ & & $-1(\mathrm{NaCl})$ & 4.84 & 98.2 \\
\hline \multicolumn{6}{|c|}{ Table 7: Optimization of rehydration ratio. } \\
\hline Source & DF & SS & MS & $\mathbf{F}$ & $\mathbf{P}$ \\
\hline Regression & 9 & 1720.35 & 191.15 & 9.41 & 0.000 \\
\hline Error & 17 & 345.48 & 20.32 & & \\
\hline Total & 26 & 2065.83 & & & \\
\hline
\end{tabular}

Table 8: ANOVA for full second order model for Shrinkage percentage.

$80^{\circ} \mathrm{C}$, potato cube size of $1 \mathrm{~cm}$ and blanching chemical $\mathrm{NaCl}$.

The result obtained might be due to the low residence time of the sample in oven at high temperature i.e. $80^{\circ} \mathrm{C}$ which results in lower shrinkage and higher rehydration potential.

\section{Effect of drying on shrinkage percentage}

The maximum and minimum shrinkage percentages were also affected by all the three parameters, not by an individual parameter. The minimum shrinkage percentage is the desirable characteristic of the dried potato samples. And it was found to be minimum for a combination of $1.5 \mathrm{~cm}$ cube size, KMS as the blanching chemical and at $80^{\circ} \mathrm{C}$ drying temperature.

ANOVA of the regression of second order model for the shrinkage percentage are given in Table 8. The Table shows that the F-value is 9.41, 
Citation: Faisal S, Tabassum R, Kumar V (2013) Performance Evaluation and Process Optimization of Potato Drying using Hot Air Oven. J Food Process Technol 4: 273. doi:10.4172/2157-7110.1000273

Page 6 of 9

which is greater than the tabulated value hence the modelis significant with coefficient of determination, $\mathrm{R}^{2}$ equals to $83.3 \%$.

The regression coefficient and probability of factor influencing the response at linear, quadratic and interactive levels are reported in Table 9. The predicted values of percent shrinkage are computed by the model for all the experimental conditions to assess the difference between observed and predicted values as reported in Table 10.

The effect of drying air temperature and cube size was significant at $\mathrm{P}<0.01$, while chemical treatment was significant at $\mathrm{P}<0.05$. In quadratic terms, drying air temperature was significantly effective at $\mathrm{P}<0.05$. The effect of sample size and the chemical treatment was insignificant on shrinkage percentage value at quadratic level. The interaction of drying air temperature, cube size, and the chemical treatment was insignificant.

The combined effect of parameters at linear, square and interactive levels on shrinkage percentage is reported in Table 11. For individual terms, the combined effect of all three variables is significant at $\mathrm{F}<0.01$. For the linear terms, the combined effect of temperature, cube size and the blanching chemical are all significant at $\mathrm{F}<0.01$. In quadratic terms all the three variables are insignificant. The interactive terms were also not showing any significant combined effect for all the combinations of the variables.

\section{Optimization of shrinkage percentage}

The results of optimization are shown in Table 12. The optimum

\begin{tabular}{|c|c|c|}
\hline Predictor & Coefficient & P \\
\hline Constant & 22.029 & 0.000 \\
\hline$X_{1}$ & -6.643 & 0.000 \\
\hline$X_{2}$ & -5.994 & 0.000 \\
\hline$X_{3}$ & -2.468 & 0.033 \\
\hline$X_{1}^{2}$ & 5.160 & 0.012 \\
\hline$X_{2}^{2}$ & 0.094 & 0.960 \\
\hline$X_{3}^{2}$ & -0.599 & 0.749 \\
\hline$X_{1} X_{2}$ & 0.220 & 0.868 \\
\hline$X_{1} X_{3}$ & 0.522 & \\
\hline$X_{2} X_{3}$ & -0.564 & \\
\hline
\end{tabular}

Table 9: Regression coefficient of full second order model for shrinkage ratio.

\begin{tabular}{|c|c|c|c|c|c|}
\hline \multirow{2}{*}{ Expt. No. } & \multirow{2}{*}{$X_{1}$} & \multirow{2}{*}{$x_{2}$} & \multirow{2}{*}{$X_{3}$} & \multicolumn{2}{|c|}{ \%Shrinkage } \\
\hline & & & & Obs. & Pred. \\
\hline 1 & -1 & -1 & -1 & 36.55 & 41.967 \\
\hline 2 & -1 & -1 & 0 & 40.94 & 40.14 \\
\hline 3 & -1 & -1 & 1 & 36.55 & 37.115 \\
\hline 4 & -1 & 0 & -1 & 39.633 & 36.223 \\
\hline 5 & -1 & 0 & 0 & 41.86 & 33.832 \\
\hline 6 & -1 & 0 & 1 & 28.06 & 30.243 \\
\hline 7 & -1 & 1 & -1 & 30.86 & 30.667 \\
\hline 8 & -1 & 1 & 0 & 22.5 & 27.712 \\
\hline 9 & -1 & 1 & 1 & 24.5 & 23.559 \\
\hline 10 & 0 & -1 & -1 & 30.1 & 29.422 \\
\hline 11 & 0 & -1 & 0 & 25.9 & 28.117 \\
\hline 12 & 0 & -1 & 1 & 39.6 & 25.614 \\
\hline 13 & 0 & 0 & -1 & 25.06 & 23.898 \\
\hline 14 & 0 & 0 & 0 & 25.33 & 22.029 \\
\hline 15 & 0 & 0 & 1 & 12.66 & 18.962 \\
\hline 16 & 0 & 1 & -1 & 16.5 & 18.562 \\
\hline 17 & 0 & 1 & 0 & 15.5 & 16.129 \\
\hline 18 & 0 & 1 & 1 & 15 & 12.498 \\
\hline 19 & 1 & -1 & -1 & 26 & 27.197 \\
\hline 20 & 1 & -1 & 0 & 29.6 & 26.414 \\
\hline 21 & 1 & -1 & 1 & 25.6 & 24.433 \\
\hline 22 & 1 & 0 & -1 & 25.9 & 21.893 \\
\hline 23 & 1 & 0 & 0 & 12.26 & 20.546 \\
\hline 24 & 1 & 0 & 1 & 14.86 & 18.001 \\
\hline 25 & 1 & 1 & -1 & 16 & 16.777 \\
\hline 26 & 1 & 1 & 0 & 15.89 & 14.866 \\
\hline 27 & 1 & 1 & 1 & 15.77 & 11.757 \\
\hline
\end{tabular}

$F_{(4,17,0.01)}=4.67, F_{(4,17,0.05)}=2.97, F_{(3,17,0.01)}=5.19, F_{(3,17.0 .05)}=3.20$

Significant at: ${ }^{* *} \mathrm{~F}<0.01{ }^{*} \mathrm{~F}<0.05$

Table 10: Effect of drying on shrinkage percentage. 


\begin{tabular}{|c|c|c|c|c|c|}
\hline \multicolumn{2}{|c|}{ SOURCE } & \multirow{2}{*}{$\begin{array}{c}\text { Degrees of Freedom } \\
4\end{array}$} & \multirow{2}{*}{$\begin{array}{c}\text { SS } \\
957.9\end{array}$} & \multirow{2}{*}{$\begin{array}{c}\text { MSS } \\
239.47\end{array}$} & \multirow{2}{*}{$\begin{array}{c}\mathbf{F}_{\mathrm{c}} \text { values } \\
11.78^{* *}\end{array}$} \\
\hline & $\mathrm{X}_{1}$ & & & & \\
\hline \multirow[b]{2}{*}{ Individual } & $\mathrm{X}_{2}$ & 4 & 651.25 & 162.81 & $8.01^{* *}$ \\
\hline & $x_{3}$ & 4 & 118.83 & 29.7 & 1.46 \\
\hline Linear & $X_{1}, X_{2}, X_{3}$ & 3 & 1550.75 & 516.9 & $25.43^{* *}$ \\
\hline Quadratic & $\mathrm{X}_{1}^{2}, \mathrm{X}_{2}^{2}, \mathrm{X}_{3}^{2}$ & 3 & 161.93 & 53.97 & 2.65 \\
\hline Interactive & $\left(X_{1} X_{2}\right),\left(X_{1} X_{3}\right),\left(X_{2} X_{3}\right)$ & 3 & 7.67 & 2.556 & 0.1257 \\
\hline
\end{tabular}

Table 11: ANOVA for total effect of individual parameter, linear, interactive and square terms on Shrinkage Percentage for different samples.

\begin{tabular}{|c|c|c|c|}
\hline Temperature & Size & Chemicals & Shrinkage Percentage \\
\hline $0.64\left(\approx 80^{\circ} \mathrm{C}\right)$ & $0.92(\approx 2 \mathrm{~cm})$ & $1(\mathrm{NaMS})$ & 12.19 \\
\hline
\end{tabular}

Table 12: Optimization of shrinkage percentage.

\begin{tabular}{|c|c|c|c|c|}
\hline Source & DF & SS & MS & P \\
\hline Regression & 9 & 19.1389 & 2.1265 & 17.67 \\
\hline Error & 17 & 2.0463 & 0.1204 & \\
\hline Total & 26 & 21.1852 & \\
\hline
\end{tabular}

Table 13: ANOVA for full second order model for overall acceptability.

\begin{tabular}{|c|c|c|}
\hline Predictor & Coefficient & P \\
\hline Constant & 4.4815 & 0.000 \\
\hline$X_{1}$ & 0.05556 & 0.506 \\
\hline$X_{2}$ & -0.05556 & 0.506 \\
\hline$X_{3}$ & 0.88889 & 0.000 \\
\hline$X_{1}^{2}$ & 0.0556 & 0.700 \\
\hline$X_{2}^{2}$ & 0.3889 & 0.014 \\
\hline$X_{3}^{2}$ & -0.7778 & 0.000 \\
\hline$X_{1} X_{2}$ & -0.0833 & 0.417 \\
\hline$X_{1} X_{3}$ & -0.0833 & \\
\hline$X_{2} X_{3}$ & 0.0833 \\
\hline
\end{tabular}

Table 14: Regression coefficient of full second order model for overall acceptability.

Shrinkage Percentage was found to be $12.19 \%$ at the temperature at temperature of $80^{\circ} \mathrm{C}$, potato cubes size of $2 \mathrm{~cm}$ and blanching chemical $\mathrm{Na}_{2} \mathrm{~S}_{2} \mathrm{O}_{5}$. The desirability of the results was $100 \%$.

The results obtained might be due to high residence time of the samples in the oven which results in lower shrinkage of the capillaries in the potato cubes.

\section{Effect of drying on over all acceptability}

The mean score of Over All acceptability was found to be maximum i.e 5 for most of the potato cubes dried at $80^{\circ} \mathrm{C}$ and of sample size $2 \mathrm{~cm}$ and chemical treatments of KMS and NaMS.

ANOVA of the regression of second order model for the Over All Acceptability are given in Table 13. The Table shows that the F-value is 17.67 and the model is significant with coefficient of determination, $\mathrm{R}^{2}$ $90.3 \%$.

The regression coefficient and probability of factor influencing the response at linear, quadratic and interactive levels are reported in Table 14. The predicted values of Overall acceptability are computed by the model for all the experimental conditions to assess the difference between observed and predicted values as reported in Table 15.

\section{Effect of variables}

The effect of the chemical treatment was significant at $\mathrm{P}<0.01$ on the over All Acceptability. The effect of drying air temperature and cube size was insignificant. In quadratic terms, drying air temperature was insignificant while the effect of sample size was significant effective at $\mathrm{P}<0.05$. The effect of the chemical treatment was significant on Over All Acceptability value at $\mathrm{P}<0.01$. The interaction of drying air temperature, cube size, and the chemical treatment was insignificant.

The combined effect of parameters at linear, square and interactive levels on Over All Acceptability is reported in Table 16.

For individual terms, the combined effect of chemical treatment is significant at $\mathrm{F}<0.01$, while the combined effect of sample size and drying temperature on the Over All Acceptability is insignificant. For the linear terms, the combined effect of temperature, cube size and the blanching chemical are all significant at $\mathrm{F}<0.01$. In quadratic terms all the three variables are significant at $\mathrm{F}<0.01$. The interactive terms were also significant at $\mathrm{F}<0.01$.

\section{Optimization of overall acceptability}

The results of optimization are shown in Table 17. The optimum value of mean sensory score of Over-All-Acceptability was found to be 5 at drying temperature of $60^{\circ} \mathrm{C}$, potato cube size of $2 \mathrm{~cm}$ and blanching chemical KMS with a desirability of $100 \%$.

This might be because of the extent of browning is less at lower temperature due to caramalization so it gives light yellow appearance of dried samples of potato cubes which in turn appeals the consumers more.

\section{Compromise optimum response}

In order to obtain a finished product of good quality, it is desirable 
Citation: Faisal S, Tabassum R, Kumar V (2013) Performance Evaluation and Process Optimization of Potato Drying using Hot Air Oven. J Food Process Technol 4: 273. doi:10.4172/2157-7110.1000273

Page 8 of 9

\begin{tabular}{|c|c|c|c|c|c|}
\hline \multirow{2}{*}{ Expt. No. } & \multirow{2}{*}{$x_{1}$} & \multirow{2}{*}{$x_{2}$} & \multirow{2}{*}{$x_{3}$} & \multicolumn{2}{|c|}{ OAA } \\
\hline & & & & Obs. & Pred. \\
\hline 1 & -1 & -1 & -1 & 3 & 3.176 \\
\hline 2 & -1 & -1 & 0 & 5 & 4.843 \\
\hline 3 & -1 & -1 & 1 & 5 & 4.954 \\
\hline 4 & -1 & 0 & -1 & 3 & 2.732 \\
\hline 5 & -1 & 0 & 0 & 4 & 4.482 \\
\hline 6 & -1 & 0 & 1 & 5 & 4.676 \\
\hline 7 & -1 & 1 & -1 & 3 & 3.065 \\
\hline 8 & -1 & 1 & 0 & 5 & 4.898 \\
\hline 9 & -1 & 1 & 1 & 5 & 5.176 \\
\hline 10 & 0 & -1 & -1 & 3 & 3.343 \\
\hline 11 & 0 & -1 & 0 & 5 & 4.926 \\
\hline 12 & 0 & -1 & 1 & 5 & 4.954 \\
\hline 13 & 0 & 0 & -1 & 3 & 2.815 \\
\hline 14 & 0 & 0 & 0 & 5 & 4.482 \\
\hline 15 & 0 & 0 & 1 & 4 & 4.593 \\
\hline 16 & 0 & 1 & -1 & 3 & 3.065 \\
\hline 17 & 0 & 1 & 0 & 5 & 4.815 \\
\hline 18 & 0 & 1 & 1 & 5 & 5.009 \\
\hline 19 & 1 & -1 & -1 & 5 & 3.620 \\
\hline 20 & 1 & -1 & 0 & 5 & 5.120 \\
\hline 21 & 1 & -1 & 1 & 5 & 5.065 \\
\hline 22 & 1 & 0 & -1 & 3 & 3.009 \\
\hline 23 & 1 & 0 & 0 & 4 & 4.593 \\
\hline 24 & 1 & 0 & 1 & 5 & 4.620 \\
\hline 25 & 1 & 1 & -1 & 3 & 3.176 \\
\hline 26 & 1 & 1 & 0 & 5 & 4.843 \\
\hline 27 & 1 & 1 & 1 & 5 & 4.954 \\
\hline
\end{tabular}

Table 15: Values of overall acceptability.

\begin{tabular}{|c|c|c|c|c|}
\hline \multicolumn{2}{|c|}{ SOURCE } & Degrees of Freedom & SS & MSS \\
\hline & $\mathrm{X}_{1}$ & 4 & 0.2407 & 0.060175 \\
\cline { 2 - 5 } & $\mathrm{X}_{2}$ & 4 & 1.1296 & 0.2824 \\
\hline Individual & $\mathrm{X}_{3}$ & 4 & 18.0184 & 4.5046 \\
\hline Linear & $\mathrm{X}_{1} \mathrm{X}_{2}, \mathrm{X}_{3}$ & 3 & 14.3334 & 4.3455 \\
\hline Quadratic & $\mathrm{X}_{1}^{2}, \mathrm{X}_{2}^{2}, \mathrm{X}_{3}^{2}$ & 3 & 4.5555 & $37.4^{\star *}$ \\
\hline Interactive & $\mathrm{X}_{1} \mathrm{X}_{2}, \mathrm{X}_{1} \mathrm{X}_{3}, \mathrm{X}_{2} \mathrm{X}_{3}$ & 3 & 0.2499 & 1.5185 \\
\hline
\end{tabular}

$F_{(4,17,0.01)}=4.67, F_{(4,17,0.05)}=2.97, F_{(3,17,0.01)}=5.19, F_{(3,17,0.05)}=3.20$

Significant at: ${ }^{* *} \mathrm{~F}<0.01{ }^{*} \mathrm{~F}<0.05$

Table 16: ANOVA for total effect of individual parameter, linear, interactive and square terms on Over-All Acceptability for different samples.

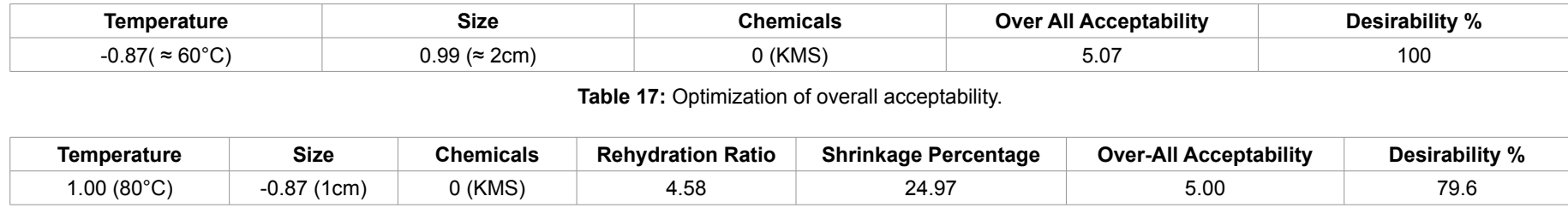

Table 18: Compromise optimize values of the response variables.

that rehydration ratio and mean sensory score of overall acceptability responses should be high and the shrinkage percentage should be low. Further the previous analysis indicates that the Over-All acceptability is affected, significantly, only by the blanching solution. The compromise optimum points for the different sizes, temperatures and blanching chemicals were estimated using Design Expert Software, with respect to all the responses. The compromise optimum points are given in Table 18 and revealed that $1.0 \mathrm{~cm}$ cube size gives a product better than that for the 1.5 and $2.0 \mathrm{~cm}$ cube sizes.
From Table 18 it was found that $1.0 \mathrm{~cm}$ cube sizes gives better responses at $1 \% \mathrm{KMS}$ as blanching solution and at $80^{\circ} \mathrm{C}$ drying temperature with a desirability of about $80 \%(\approx 79.6 \%)$. This might be because of the less residence time of samples in the oven at higher temperature, which in turn revealed less shrinkage and deterioration in color and consequently better rehydration of samples.

\section{Conclusions}

The following conclusions were drawn from the results of this study: 
Citation: Faisal S, Tabassum R, Kumar V (2013) Performance Evaluation and Process Optimization of Potato Drying using Hot Air Oven. J Food Process Technol 4: 273. doi:10.4172/2157-7110.1000273

Page 9 of 9

1. The rate of moisture content depletion was dependent on all the three variables, and the moisture content depletion was higher at high temperature and for small cube size. While as the moisture depletion was quicker for $\mathrm{NaCl}$ and slowest for $\mathrm{NaMS}$.

2. The moisture ratio curves could be mathematically described satisfactorily by Midilli’s model.

3. Drying time increases as the temperature decreases and the cube size increases.

4. The rehydration ratio is high for the samples dried at higher temperatures and for the smaller cube sizes. It was also high when $2 \% \mathrm{NaCl}$ was used as the blanching chemical.

5. Shrinkage Percentage was lower for high drying temperature and $1.5 \mathrm{~cm}$ cube size and 1\% KMS blanching solution.

6. Over All Acceptability was found to be maximum for KMS and NaMS blanching solutions and was higher at $80^{\circ} \mathrm{C}$ drying temperature and for larger cube sizes. Over All acceptability was mainly dependent on the blanching chemical as it mainly depends upon appearance i.e. extent of browning.

7. Compromise optimum level of the three variables (i.e. drying temperature, sample cube size and the blanching chemical) for the responses, namely, rehydration ratio, shrinkage percentage and over all acceptability was $80^{\circ} \mathrm{C}$ (coded value $\left.=1\right), 1 \mathrm{~cm}$ cube size ( coded value $=-0.87$ ) and KMS. The corresponding values of the responses were $4.58415,24.9798$ and 5 respectively.

8. Contour plots showing the effect of variables on responses at center point and compromise optimum points reveal that the range of variables are higher at optimum point than at central point.

9. The dehydrated cubes stored very well in polyethylene and HDPE bags for a period of over 72 days and their overall acceptability was satisfactory.

\section{References}

1. Marwaha RS, Dinesh K, Singh SV (1999) Chipping \& nutritional qualities of Indian and exotic Potato processing varieties stored under different conditions. Journal of Food Science \& Technology 46: 354-358.

2. Greensmith M (1998) Practical Dehydration. Woodhead Publishing

3. McMinn WAM, Magee TRA (1999) Studies on the Effect of Surfactant Blanching and Osmotic Pretreatments on the Convective Drying of Potatoes. J Food Process Eng 22: 419-433.

4. Nath N, Katara DK (1985) Effect of pre-treatments on quality of dried potato cubes. Indian Food packer 39: 23-26.

5. Burande RR (1992) Optimization of process variables in fluid bed drying of peas. Thesis, M.Tech, G.B.Pant University of Agriculture and Technology, Pantnagar.

6. Pandey $H$ (2001) Optimization of process parameter of dehyadration of cauliflower. Thesis, M.Tech, G.B. Pant University of Agriculture and Technology, Pantnagar.

7. Goyal (2002) Optimization of Two Stage Drying Process and Storage Behavio of De-hydrated Potato Cubes, Thesis, M.Tech, G.B.Pant University of Agriculture and Technology, Pantnagar.

8. Ho Minh T, Athapol N (2011) Modelling and Effects of Various Drying Methods on Sweet Potato Starch Properties. Walailak Journal of Science and Technology 8: 139-158.

9. Rangana S (1986) Handbook of Analysis and Quality Control for Fruit and Vegetable Products. $2^{\text {nd }}$ ed. Tata McGraw Hill Publishing Co. Ltd., New Delhi. 